\title{
O HOMO CALAMITATEM: A COMUNICAÇÃO DE RISCOS E DE CATÁSTROFES NA EVOLUÇÃO DA INSEGURANÇA SOCIAL
}

\author{
THE HOMO CALAMITATEM: THE CATHASTROFE AND RISK COMMUNICACION IN
}

THE EVOLUTION OF THE SOCIAL INSECURITY

EL HOMO CALAMITATEM: LA COMUNICACIÓN DE RIESGOS Y CATÁSTROFES EN LA EVOLUCIÓN DE LA INSEGURIDAD SOCIAL

\author{
Carlos Lozano Ascencio \\ Professor da Universidad Rey Juan Carlos \\ carlos.lozano@urjc.es \\ Márcia Franz Amaral \\ Professora da Universidade Federal de Santa Maria \\ marcia.amaral@ufsm.br
}

\begin{abstract}
Resumo
Homo calamitatem é entendido como o "homem calamitoso e desastroso", autor e promotor de muitos dos grandes riscos e catástrofes que afetam nossas sociedades contemporâneas. $\mathrm{O}$ trabalho reflete sobre a comunicação de riscos e catástrofes na evolução social de insegurança e as distintas formas históricas em que o ser humano se organizou para enfrentar as incertezas em seus entornos, até chegar a ser a principal causa desses riscos e catástrofes que tanto nos afetam.
\end{abstract}

Palavras- chave: Comunicação de risco. Catástrofe. Insegurança Social. Sociedade de risco.

\begin{abstract}
Homo calamitatem is understood as "the dire or disastrous Man", author and promoter of many of the major risks and catastrophes that affect our contemporary societies. For its part, the communication of risks and disasters in the evolution of social insecurity refers to the various historical forms in which the human being is organized to how to face the uncertainty of the environment, up to become the main cause of such risks and disasters that affect us both.
\end{abstract}

Key words: Risk Communication. Catastrophe. Social insecurity. Risk society.

\section{Resumen}

Homo calamitatem se entiende como "el hombre calamitoso o desastroso", autor y promotor de muchos de los grandes riesgos y catástrofes que afectan a nuestras sociedades contemporáneas. Por su parte, la comunicación de riesgos y catástrofes en la evolución social de la inseguridad se refiere a las distintas formas históricas en las que el ser humano se ha organizado para saber enfrentarse a la incertidumbre de los entornos circundantes, hasta llegar a convertirse en el causante principal de esos riesgos y catástrofes que tanto nos afectan.

Palabras clave: Comunicación de riesgo. Catástrofe. Inseguridad social. Sociedad del riesgo. 


\section{INTRODUCCIÓN}

Los entornos urbanos han sido, básicamente, una de las principales formas que le ha servido históricamente a la humanidad tanto para preservar su supervivencia y su seguridad como para distanciarse física y culturalmente de los peligros. Hoy en día, sin embargo, son los entornos urbanos los principales escenarios en donde no sólo se propician los mayores riesgos sino, sobre todo, donde se registran las repercusiones y los daños más relevantes e importantes a la hora de registrar las amenazas y medir la destrucción. Es decir, lo que primero sirvió para que los hombres pudiesen defenderse y aislarse de la adversidad, hoy los sitúa de frente, sin barreras, con los infortunios de una época (la actual) en la que se ha incrementado tanto la fabricación de riesgos (niveles de vulnerabilidad) así como el número de catástrofes destructivas (niveles de vulneración).

Desde los inicios de la humanidad los entornos urbanos se construyeron (se fundaron) y se fortificaron (con murallas, paredes, vallas y cercas) para "proteger" a los grupos humanos de los peligros externos, pero en la actualidad, los entornos urbanos son los lugares donde se corren más riesgos porque cada vez estamos más expuestos tanto a los peligros tradicionales: los que son propios y frecuentes de cada región y cultura; como a los peligros de nuevo cuño: los que comienzan a ser más frecuentes aunque no sean propios de cada región y cultura.

Las antiguas fortificaciones urbanas, que en otros tiempos les sirvieron a los seres humanos para defendernos de los peligros externos, hoy en día han perdido su funcionalidad original y se han convertido, en el mejor de los casos, en reclamos turísticos. La salvaguarda de la seguridad ya no precisa de la construcción de grandes barreras físicas, sino más bien tiene que ver con la habilitación de vigentes cortafuegos y antivirus informáticos que filtren los flujos informativos por donde circula a sus anchas la incertidumbre. La inseguridad se va incorporando y asentando cada vez más en la vida pública de las sociedades y en la vida privada de los ciudadanos. Las distinciones entre lo que en teoría está bajo control y lo que no lo está, es decir, lo que nos brinda seguridad o inseguridad son delimitaciones "confusamente claras" o "claramente confusas" que le dan identidad desastrosa a la época que nos ha tocado vivir. En la actualidad, la especie dominante se ha convertido en autora y promotora de los grandes riesgos y catástrofes. 


\section{ESPECIE URBANIZADORA (HOMO URBANUS)}

La especie humana, básicamente, es una "especie urbanizadora”. Usamos aquí el adjetivo "urbanizadora" no como una noción opuesta a lo rural y a lo rústico, sino como una caracterización de la especie humana a la hora de afrontar su propio desarrollo evolutivo en función de la continua e interminable edificación de entornos de supervivencia. Los homo urbanus son seres constructores de entornos artificiales que, a diferencia de otras especies animales -también constructoras como los insectos (panales u hormigueros), aves (nidos), mamíferos inferiores (madrigueras)-, tienen la capacidad de modificar los entornos circundantes erigiendo lindes para distinguir a la naturaleza de los espacios construidos. No sólo se trata de una diferencia física que serviría para guarecerse de peligros y para preservar la supervivencia, sino que también se trataría de una diferenciación simbólica que separa las cosas naturales de las cosas sometidas a las finalidades humanas.

Cuando la especie humana consiguió diferenciarse del entorno natural se convirtió en homo urbanus porque, en esencia, se auto-construyó un "dominio urbano de supervivencia" para todos los miembros del grupo. Dicho dominio, hecho con piedras y adobe, le permitió a la humanidad realizar un despegue cultural sin precedentes porque se pudo apreciar con mucha más claridad la dicotomía "dentro/fuera". En un principio, todo lo que estaba afuera se relacionaba con lo malo, lo desconocido y los temores implícitos; en la lejanía no se percibía con detalle, y si se percibía algo se llevaba a cabo sensorialmente a distancia o, incluso, extra sensorialmente. Más tarde, lo de afuera se relacionaba con todo lo que estaba al margen de la ley y de las normas de convivencia, lo que aún no tenía explicación y, por supuesto, no tenía ningún tipo de utilidad práctica. Ahí afuera, del otro lado de las barreras de piedra, estaba todo lo que se relacionaba con la incertidumbre, la aversión y, sobre todo, con la inseguridad.

Lo de adentro, en cambio, siempre se relacionaba con lo bueno y lo conocido, con la proximidad sensorial, con lo aceptado por todos, con las leyes de la cohabitación, con las explicaciones (mitológicas y científicas) y las aplicaciones prácticas (rituales y tecnológicas) que más se utilizaban y que convirtieron al entorno en un hábitat mucho más comprensible, confortable, seguro y, en definitiva, más humano.

En el Cuadro 1, el lector puede observar que la evolución histórica de la percepción de la seguridad y la inseguridad tiene que ver con tres elementos relacionados: 1) la diferenciación entre los entornos naturales y urbanos; 2) el uso del conocimiento disponible en cada momento y lugar para saber percibir e interpretar los entornos naturales y urbanos, y 
3) el origen, responsabilidad o causalidad de las explicaciones ofrecidas para saber percibir e interpretar los entornos naturales y urbanos.

Cuadro 1. Evolución histórica de la percepción de la inseguridad

\begin{tabular}{|l|c|c|}
\hline Entornos naturales y urbanos & $\begin{array}{c}\text { Conocimiento } \\
\text { disponible }\end{array}$ & $\begin{array}{c}\text { Origen (culpable o } \\
\text { responsable) de la } \\
\text { inseguridad }\end{array}$ \\
\hline No interpretados & - & - \\
\hline $\begin{array}{l}\text { Percibidos pero aún } \\
\text { incomprensibles }\end{array}$ & Mitológico & Mítico \\
\hline Poco conocidos & Mitológico y Científico & Mítico y Autógena \\
\hline Suficientemente conocidos & Científico & Autógeno y Antrópico \\
\hline
\end{tabular}

Fuente: Elaboracion propia

Los entornos percibidos pero aún incomprensibles fundamentan sus significados en fábulas y leyendas que brindan explicaciones sobre lo acontecido, por lo general se trata de aseveraciones míticas que trasladan la responsabilidad de lo ocurrido al enfado de los dioses. En los entornos poco conocidos los sujetos hacen uso de información mitológica y científica en ciernes con la posibilidad no sólo de culpar a los dioses de los infortunios ocurridos sino, de ampliar la responsabilidad a la autogeneración de fenómenos violentos y destructivos. Los entornos suficientemente conocidos, propios de las sociedades modernas, se analizan utilizando el conocimiento científico socialmente disponible para cada época para dilucidar si el origen del riesgo o de la catástrofe tiene una causa autógena (generada por la propia naturaleza) y/o antrópica (generada por la actividad humana).

\subsection{Los Dominios Urbanos}

Es cierto que los entornos urbanos se construyeron para defender la vida y la identidad de los grupos humanos, pero también es cierto que las necesidades de guarecerse de los peligros y de preservar la existencia fueron, sobre todo, reacciones y respuestas anticipadas a la presión que ejerció la naturaleza sobre los grupos humanos. En consecuencia, las primeras moradas que se edificaron artificialmente, según lo expuesto, no surgieron de manera espontánea, como las setas en el campo, sino precedidas de una fuerte presión medioambiental sobre los seres humanos. Tales presiones externas, dicho sea de paso, han ido agudizando el ingenio humano (en cualquier época histórica) para poner en marcha, individual y/o colectivamente, toda clase de mecanismos de supervivencia. 
Si intentemos situar históricamente a los primeros homo urbanus, albañiles de entornos artificiales (aldeas) en plena naturaleza y escasamente poblados, tendríamos que remitirnos a finales del paleolítico, hace tan sólo quince mil años. La presión externa podría estar protagonizada por la gran glaciación que empujó a los grupos humanos a deambular en busca de entornos naturales más asequibles para la supervivencia. En tales condiciones, creció la demanda de alimento, los cazadores intensificaron las capturas masivas y se extinguió la mega fauna. Las hambrunas hicieron mella en la población.

\subsection{Dominio Urbano: Domesticación de la Naturaleza}

Las primeras moradas que construyeron los seres humanos coincidieron con el inicio de la era neolítica. Esa primera gran revolución de la humanidad destacó, sobre todo, por la “domesticación” del entorno natural. "La etimología de la voz 'domesticar' es la misma que 'domar' o 'dominar', pues ambas derivan de dominus: en latín, señor' (GIL CALVO, 2003, p. 140). La "domesticación” del entorno natural no sólo fue el control agrícola y ganadero de la alimentación, sino que también fue el manejo de variadas técnicas para mejorar la caza (arco y flecha), para almacenar alimentos (alfarería), para trasladar materiales pesados (rueda y carro), etc. La “domesticación” del entorno natural también consistió en establecer el "domicilio" (sedentarismo) desde el cual los hombres intentaron "domeñar" o someter al mundo en función de sus propios intereses de convivencia.

No podemos pasar por alto que desde los comienzos de la convivencia grupal, en el interior de los primeros entornos urbanos, surgen inevitablemente peligros que no proceden del mundo exterior sino que se generaron interiormente. Hablamos de las epidemias contagiosas que se transmiten por los nuevos animales domésticos y que se propagaron más fácilmente por el hacinamiento de la población urbana.

\subsection{Vestigios de Vida Urbana}

Cuando se descubre un vestigio urbano se suele interpretar tomando en consideración algunos de los siguientes aspectos: la concentración de actividades improductivas; la densidad poblacional del espacio; las formas culturales y comerciales propias; el desarrollo de actividad científica; y, sobre todo, las formas de organización política-administrativa, en las que, además de asegurar el funcionamiento de la vida urbana, se detecta la dominación de una 
clase social sobre otra. En este sentido, los yacimientos más antiguos de los dominios urbanos $\mathrm{y}$, en especial, de los dominios de vidas urbanas son los asentamientos sedentarios y relativamente densos de población que se sitúan al final del periodo neolítico, destacando en importancia Mesopotamia, Egipto, China e India entre el 3500 al 2500 antes de nuestra era. En estos asentamientos la vida urbana se lleva a cabo principalmente por algunos miembros cuya estancia directa en el campo de cultivo y en la producción agrícola no era necesaria; se trata de sacerdotes, escribas, administradores y políticos que representan la parte dominante de las nuevas relaciones sociales de poder.

\subsection{Cuando "ciudad" significaba "seguridad"}

Así como el útero materno protege y posibilita la reproducción biológica, y el hogar familiar cuida y facilita la formación individual, la ciudad también es un ámbito protector de la existencia y el desarrollo de las sociedades. Es verdad que las ciudades siempre tratan de garantizar la seguridad de sus ciudadanos frente a las agresiones enemigas y externas. Para ello, durante siglos, el amurallamiento se convierte en la práctica más habitual de defensa de las ciudades hasta que dicho papel posteriormente se le asigna a los Estados.

Pero vayamos por partes, las ciudades-estados grecorromanas compatibilizan los entornos urbanos amurallados (fronteras de seguridad hacia el exterior) con los espacios abiertos y públicos (fronteras de libertad hacia el interior); así, obras tan destacadas como el ágora, el foro, las termas, el anfiteatro, el circo, el gimnasio, posibilitan una vida urbana dialogante (democrática) aunque no para todas las clases sociales, sino solamente para los ciudadanos libres. De las sociedades esclavistas grecorromanas podemos destacar dos ejemplos en los que las murallas no ayudan a preservar la seguridad de sus ciudadanos. $L a$ peste de Atenas referida por Tucídides en su obra La guerra del Peloponeso (428 a.d.n.e.) y La erupción del Vesubio que destruyó Pompeya y Herculano, relatada por Plinio El Joven (79 d.n.e). En ambos casos los relatos de las quiebras del acontecer que destruyeron los entornos urbanos se convirtieron, quizá por primera vez, en los escenarios más significativos e importantes a la hora de registrar y medir la destrucción catastrófica.

Las ciudades medievales, incluso las que aún pueden visitarse, destacan por sus fuertes fortificaciones que no sólo sirven para resguardar a las poblaciones de los peligros exteriores sino también para ensimismar más a sus pobladores en un ambiente muy estructurado y cerrado en cuanto a ideas políticas y religiosas. En aquellos burgos los habitantes no tenían mucha claridad para diferenciar entre los espacios públicos y privados; la 
seguridad era una razón celestial y las situaciones de inestabilidad se percibían y se explicaban como castigos divinos. La vida urbana, en esta larga época, quedaba aislada de los asuntos de interés general hasta que la nueva clase social burguesa, en su frontal resistencia al feudalismo, suscribe nuevos valores de ahorro económico e inversión financiera para dinamizar los mercados de ciudades portuarias como Génova o Venecia. Si los puertos y sus habitantes se abren al tráfico de mercancías (y de información manuscrita) también se exponen con mayor facilidad al contagio de enfermedades. A mediados del siglo XIV, un gran número de ciudades europeas se enfrentan a una de las mayores situaciones de inestabilidad de la Historia: la peste negra. Las consecuencias de esta catástrofe europea, con más de veinte millones de muertos, marcan radicalmente la vida urbana medieval como punto de inflexión hacia una sociedad diferente (la renacentista) ${ }^{1}$.

En las ciudades "pre-modernas" (entre 1450-1750) la seguridad de la vida urbana estaba respaldada por la consolidación de los distintos Estados absolutistas. Los soberanos responden directamente ante Dios y no están someditos ni al Papa ni al Emperador, ni tampoco rinden cuentas a sus propios vasallos. La famosa frase atribuida a Luis XIV "el Estado soy yo", simboliza perfectamente la concentración de poder en el monarca. La inestabilidad social, por tanto, no se percibe directamente, comienza a ser desbancada por la oficialidad de los relatos del acontecer controlados por la maquinaria periodística del Estado absolutista, es decir por la manipulación de los acontecimientos en función de sus propios intereses políticos. La imprenta ofrece la posibilidad de mostrar los primeros detalles de la recreación visual de la inseguridad, los súbditos refuerzan sus creencias tremendistas al hojear los Mercurios y las Gacetas que, sin cuestionamientos, demuestran situaciones de inestabilidad social como es el caso del Incendio de la City londinense (1666), en el que arde el $80 \%$ de los edificios de la ciudad. Las explicaciones de la destrucción no son exclusivamente de carácter divino, sino más bien de carácter oficial: el fuego se inicia en una panadería, pero para justificar el alcance destructivo se dice que es provocado por conspiradores extranjeros, ya que por esos años Inglaterra está en guerra con Francia y Holanda.

Con la Ilustración las ciudades modernas (hacia 1750) tienen una vida urbana mucho más dinámica y participativa. Es la época en la que la razón intenta reunir en una magna obra

\footnotetext{
1 Se cree que la epidemia provino de Asia, probablemente de la India, y que llegó a Europa como consecuencia de los contactos comerciales que las grandes potencias mercantiles de Italia sostenían con el próximo oriente. Se piensa que la tripulación de un navío genovés, habiéndose contagiado en Kaffa (Crimea), introdujo la enfermedad desembarcando mercancías junto con ratas infectadas. Desde Italia, la peste alcanzó en 1348 la Provenza, el Languedoc, la Corona de Aragón, Castilla, Francia y el centro de Europa. En los años siguientes (1349-1350), se extiendió por Inglaterra, el norte de Europa y Escandinavia.
} 
enciclopédica los conocimientos socialmente disponibles, se re-diseñan y se re-edifican espacios urbanos para facilitar las relaciones sociales y para incentivar el interés general de una naciente opinión pública e ilustrada. La inseguridad ciudadana deja de ser un tabú y pasa a ser un tema de discusión política, un asunto opinable y, al mismo tiempo, una situación que no sólo interesa sino que concierne a todos los individuos pensantes y críticos. En 1755, el terremoto, y el consiguiente tsunami, que destroza la ciudad de Lisboa cambia radicalmente la relación entre entorno urbano y riesgo porque aunque también se explica la tragedia por causas de enfados divinos, la afectación no se centra sólo en el individuo, sino en la colectividad ciudadana. El marqués de Pombal se encarga de las tareas de reconstrucción y de apoyar los estudios que a la postre desencadenan las ciencias sismológicas.

En las ciudades modernas (hacia 1830) la vida urbana se desarrolla estrechamente con la Revolución Industrial; primero porque la emigración hacia los centros urbanos proporciona la fuerza de trabajo esencial para la industria y luego porque se salta de una economía doméstica a una de manufactura y después a una de fábrica. Se produce así una relación sinérgica entre el desarrollo de la industria y el proceso de urbanización: centro de producción = núcleo urbano. Es la época en la que los medios de transporte (ferrocarril) y de comunicación (telégrafo, periodismo industrial, agencias de información) juegan un papel determinante, reduciendo tiempos y distancias, a la hora de agilizar las interacciones sociales de la vida urbana. La inseguridad ciudadana, en este contexto, es un problema de desigualdad social para la clase obrera, pero para la clase dirigente (política y empresarial) es más bien un problema que compete a un Estado-nación (con claras delimitaciones territoriales en los mapas). Así, la ideología nacionalista "conmueve a las masas y también las moviliza tras consignas que alientan un nuevo sentimiento de pertenencia que las enorgullece: la nación aparece convertida en el moderno trasunto de comunidad que a todos integra y a todos hace sentir iguales” (GARCIA GONZÁLEZ, 1999, p. 75).

\subsection{Las Ciudades: Nuevos Escenarios del Riesgo Catastrófico}

Las ciudades más importantes del planeta durante el siglo XX comienzan a configurarse como unas auténticas trampas para la seguridad ciudadana. Es cierto que se trata de la época de los grandes avances tecnológicos en la industria y en el bienestar social, pero también destacan deshonrosos ejemplos (entre 1914 y 1945) en los que el interés militar 
convierte a las ciudades en puntos estratégicos de hazañas bélicas, ${ }^{2}$ hoy en día tristemente recordadas: hace casi ocho décadas, por ejemplo, los aviones alemanes de la Legión Cóndor bombardean la villa vizcaína de Guernika: la primera vez que una potencia militar bombardea un entorno urbano habitado de otra nación; el episodio cumbre de la destrucción urbana y ciudadana (urbanicidio) en toda la Historia de la humanidad lo representen los lanzamientos de las primeras bomba atómicas sobre las ciudades de Hiroshima y Nagasaki ${ }^{3}$.

Las principales urbes de la segunda mitad del siglo XX son, en realidad, los nuevos escenarios del riesgo. Es la época en donde el desarrollo tecnológico y productivo incrementa las contradicciones entre urbanismo y naturaleza y a su vez incrementa la inter-afectación destructiva de ambos entornos.

Si bien hoy en día se presenta un nivel de riesgo generalizado, éste se ha
trasladado -imponiéndose con mayor intensidad- hacia los contextos o
escenarios donde tiende a concentrarse masivamente la población, pero
principalmente donde confluyen los elementos determinantes que expresan
el máximo nivel de desarrollo alcanzado por el capitalismo; por ejemplo,
donde han madurado las fuerzas productivas, donde las relaciones de
producción dominantes tienen lugar, donde las relaciones sociales se
expresan de manera absoluta y donde la competencia y el mercado -
expresión principal del capitalismo- se han desarrollado de manera más
amplia. Este nuevo contexto, es decir, este nuevo escenario del riesgo es la
ciudad (MANSILLA, 2000, p.67).

Las ciudades contemporáneas, en sí mismas, no son más peligrosas que las ciudades construidas en otras épocas, algo así da pie a pensar que no ha habido avances en el conocimiento y en las técnicas constructivas. No, lo que nos hace más vulnerables al riesgo es nuestra forma de vida urbana. Citando a Anthony Giddens (2002, p. 47) podemos decir que "vivimos en un mundo donde los peligros creados por nosotros mismos son tan amenazadores, o más, que los que proceden del exterior. Algunos de ellos son verdaderamente catastróficos, como el riesgo ecológico mundial, la proliferación nuclear o el colapso de la economía mundial". En consecuencia, aunque se han eliminado riesgos que anteriormente podían tener consecuencias catastróficas para los individuos, se han ido creando otros nuevos. La fase actual de la modernidad (o de la post-modernidad) se caracteriza, por lo tanto y a partes iguales, por la creación y dotación del bienestar social así

\footnotetext{
${ }^{2}$ Hay que advertir que las consideraciones militares han tenido mayor presencia en los debates sobre urbanismo occidental realizados en el siglo XX, que lo que generalmente se cree. Stephen Graham (2004), profesor de Geografía Humana en la Universidad de Durham, Reino Unido nos dice que "un factor que influyó en los planes de Le Courbusier de los años 30 fue diseñar edificios altos para hacer menos vulnerable el espacio urbano ante emergencias técnicas o bombardeos aéreos y ataques de gas (el asunto es irónico, dado que los rascacielos son considerados, tras el 11 de septiembre [de 2001], como extremadamente vulnerables)".

${ }^{3}$ Mueren más de 300 mil personas y muchas otras quedan afectadas seriamente, incluso las que pertenecen a generaciones posteriores.
} 
como por la producción de unos riesgos cada vez más difíciles de conocer (prever/identificar), controlar (erradicar/atenuar) o gestionar (administrar/recuperar).

\section{ESPECIE ESCENIFICADORA (HOMO URBANITAS): PUESTA EN ESCENA DE LA VIDA URBANA}

Los entornos urbanos, corazas artificiales frente a lo natural, se crean, se reproducen y se expanden físicamente por el medio ambiente creando moradas, aldeas, pueblos, ciudades, urbes, complejos urbanísticos y megalópolis; los humanos que habitan (pisan) los escenarios urbanos se comportan y se relacionan con los demás de manera diferente a como lo harían antes de la construcción de dichos espacios. Javier Echeverría (1999, p.41-42) se refiere al entorno urbano como "segundo entorno" y afirma que

sus formas canónicas son los pueblos y las ciudades en las que viven la mayoría de los seres humanos. En esos espacios urbanos se han desarrollado diversas formas sociales [como la vestimenta, la familia, la persona, el individuo, el mercado, el taller, la empresa, la industria, el dinero, los bancos, las escuelas, los cementerios, la escritura, la ciencia, las máquinas, el derecho, la ciudad, la nación, el estado, las iglesias, etc.] (...) El desarrollo del segundo entorno no implica la desaparición del primero (el medio ambiente), pero sí su modificación, a veces muy profunda (...) La sociedad industrial, con sus grandes ciudades, metrópolis y megalópolis es la forma más desarrollada del segundo entorno.

Por esta razón, los entornos urbanos también se expandieron culturalmente por el orbe creando mitos, leyes, normas de conducta, códigos de comercio y de circulación, estilos de vestir, de comunicarse y de convivir con los demás. La vida urbana dio cuenta del funcionamiento de los entornos urbanos, fue algo así como "la puesta en escena" de la existencia y la reproducción de las sociedades.

El homo urbanus, tan sólo por vivir y pervivir, relacionarse y compartir, se convirtió en un homo urbanitas o diseñador de las reglas y de la convivencia de la vida urbana. En este punto hay que señalar que así como el homo urbanus (el albañil) construyó ciudades para sobrevivir, el homo urbanitas diseñó las reglas de convivencia urbana con el mismo objetivo: sobrevivir, pues para que los seres humanos se adaptaran y se desarrollaran en el entorno socio-cultural que les tocó vivir, requirieron, forzosamente, de una formación en conocimientos, normas, lenguajes y valores para poder relacionarse comunicativamente con 
los demás, de lo contrario no se habrían adaptado, ni se habrían desarrollado dado que se habrían marginado de la vida social.

Una vez que el ser humano se desarrolló como homo urbanitas (socializado según el conocimiento disponible de cada época histórica) no renunció a seguir construyendo y expandiendo sus dominios urbanos por el orbe, pero desde entonces con una impronta cultural determinante, que fue la que le permitió mantener e imponer a los demás (pueblos y culturas) un dominio cultural o estilo de vida dominante. Hay que decir que los seres humanos no alcanzaron dicha expansión cultural sin la capacidad de expresar o denominar las cosas más importantes y concernientes de los entornos circundantes (ya sean urbanos o naturales); dicha habilidad comunicativa les permitió tener el control sobre las cosas que aprendieron a nombrar o denominar. Así, el éxito no sólo radicó en la majestuosidad física de obras arquitectónicas (murallas, templos, plazas y acueductos), sino, sobre todo, en la ingeniería o funcionalidad diseñada para dichas obras urbanas. La historia de las expansiones coloniales mucho tiene que ver precisamente con la imposición de dominios culturales pero también con la imposición de dominios urbanos en los nuevos territorios. A veces, dichas imposiciones urbanísticas pueden interpretarse como aportaciones o como despropósitos tanto para la cultura dominada como para el entorno natural invadido. Javier Echeverría (1999: 47) sostiene que "la expansión del segundo entorno por todo el planeta compendia la historia humana, a diferencia de la prehistoria, caracterizada por el largo proceso de adaptación del ser humano a la naturaleza".

Desde que comenzamos a edificar nuestras primeras moradas hasta hoy en día, los seres humanos no hemos dejado de fungir como homo urbanus; seguimos urbanizando el planeta a marchas forzadas, sometiendo al entorno natural no sólo a nuestras finalidades de supervivencia, sino sobre todo a nuestros intereses de especulación económica, llegando hasta el punto de cambiar el perfil orográfico de las costas con kilómetros de cemento, edificar complejos urbanísticos en las desembocaduras naturales de los ríos, crear megalópolis superpobladas y muy contrastadas socialmente que se caracterizan no sólo por la difícil y costosa habitabilidad, sino también porque prácticamente son escenarios urbanos en donde la inseguridad ciudadana es el aspecto más característico y dominante.

Tal parece que el homo urbanus se ha convertido en el homo calamitatem y ambos se han impuesto al homo urbanitas. Lo que está claro es que la evolución de la "urbanidad" humana consiste precisamente en una progresión inacabable y calamitosa en la que los dominios humanos más dominadores se imponen sobre la naturaleza y sobre otros dominios humanos más débiles. Dicha progresión humana que quiere dominarlo todo (incluyendo 
estaciones orbitales y sondas siderales que viajan por los confines de nuestra galaxia) construye y mantiene los entornos urbanos actuales en los que habitamos y que, además, nos colocan en el centro de los infortunios de nuestra época, en la que se ha incrementado tanto la fabricación de riesgos (niveles de vulnerabilidad) así como el número de catástrofes destructivas (niveles de vulneración).

\subsection{Los Nuevos Riesgos Urbanos}

Las ciudades de nuestra época no son más seguras y estables en los márgenes del bienestar individual y colectivo, más bien los riesgos aumentan progresivamente, incrementando las posibilidades de que aparezcan crisis, tragedias y catástrofes. Si tenemos que hacer una caracterización de las urbes contemporáneas destacaríamos cinco aspectos:

a) Elefantiasis Urbana (crecimiento anormal e incontrolado de no-lugares ${ }^{4}$ ). Las ciudades crecen en condiciones altamente desfavorables, sobre todo en los países subdesarrollados. Grandes extensiones de asfalto, casas, coches y cables configuran paisajes que, como es el caso de la Ciudad de México, llegan a convertirse en un atractivo turístico para los pasajeros de los aviones que despegan o aterrizan en esa megalópolis. En algunos países desarrollados, como es el caso de España, la elefantiasis de las ciudades obedece más bien a motivos de especulación económica.

b) Superpoblación Aglomerada (no-población). Alta concentración de la población en pocas ciudades. Además de no tener un control estadístico (sanitario, educativo, laboral, etc.) se manifiesta drásticamente una profunda desigualdad social, la insuficiencia en los niveles de equipamiento e infraestructura y los efectos de las graves crisis económicas expresadas en desempleo, marginación, déficit en la vivienda y en la prestación de muchos servicios de primera necesidad. Las aglomeraciones urbanas, al demandar agua en cantidades exageradas, afectan a los cultivos de regadío; contaminan y degradan las zonas públicas con mucha rapidez y facilidad.

\footnotetext{
${ }^{4} \mathrm{El} \mathrm{no-lugar} \mathrm{"se} \mathrm{opone} \mathrm{a} \mathrm{todo} \mathrm{cuanto} \mathrm{pudiera} \mathrm{parecerse} \mathrm{a} \mathrm{un} \mathrm{punto} \mathrm{identificatorio,} \mathrm{relacional} \mathrm{e} \mathrm{histórico:} \mathrm{el}$ plano; el barrio; el límite del pueblo; la plaza pública con su iglesia; el santuario o el castillo; el monumento histórico..., enclaves asociados todos a un conjunto de potencialidades, de normativas y de interdicciones sociales o políticas, que buscan en común la domesticación del espacio. Augé clasifica como no-lugares los vestíbulos de los aeropuertos, los cajeros automáticos, las habitaciones de los hoteles, las grandes superficies comerciales, los transportes públicos, pero a la lista podría añadírsele cualquier plaza o cualquier calle céntrica de cualquier gran ciudad (...) en que proliferan 'los puntos de tránsito y las ocupaciones provisionales"” (DELGADO, 1999, p. 40. Citando a AUGÉ, 1993, p. 83)
} 
c) Polarización (contraste): Hace años que la mayor parte de la población mundial vive en ciudades, pero ahora, por primera vez, la mayoría de la población pobre del mundo habitará en las ciudades tanto de países en vías de desarrollo como de países ricos. La importante inmigración que reciben las ciudades del mundo desarrollado facilita que las ciudades vuelvan a fortificarse para separar a unos ciudadanos de otros. La polarización de la vida urbana conforma un "caldo de cultivo" ideal para el incremento y consolidación de fenómenos de fragmentación, segregación e incomunicación social. Los intercambios sociales se aprecian más bien como "mezclas étnicas" que como "relaciones interculturales". Proliferan los barrios cerrados (las gated communities) que son

espacios gestionados de forma privada, vigilados por compañías también privadas, a los que está restringido el acceso. Pero en estas ciudades cada vez más duales, junto a estos barrios exclusivos también se consiente la existencia de guetos de infravivienda, barrios sub-equipados, espacios de acogida (poca) de aquella población que molesta, espacios convenientemente separados de las comunidades de clase media. (CAZ, 2002, p.45)

d) Mayor Vulnerabilidad al Riesgo Catastrófico (más que en cualquier otra época histórica). El incremento de vulnerabilidad se debe a que estamos más expuestos a los peligros que pueden desencadenar afectaciones destructivas. Es evidente que la fragilidad al trastorno que padecemos se debe a que

Las sociedades modernas están enfrentadas con una conciencia creciente del riesgo porque cada vez hay más decisiones que se toman en una atmósfera de incertidumbre. Esta perspectiva tiene el mérito de interpretar el sentido del riesgo como una construcción social, relativa a la conciencia subjetiva dominante, más que como un reflejo ante peligros reales (...) El miedo no entiende el principio de razón suficiente. (INNERARITY, 2004, p. 152, el subrayado es nuestro)

e) La Seguridad: el Nuevo Paradigma de la Vida Social. Contratar o comprar seguridad se ha convertido en un hecho común en la mayoría de nuestras ciudades. Diferentes dispositivos se van incorporando a la estética citadina: barreras, garitas, casetas, vallas, alambradas, dobles ventanas, alarmas. Las urbanizaciones, por cierto, las que edifican con ostentación su aislamiento del entorno urbano que las rodea, cada 
vez tienen más éxito tanto en los cascos urbanos como en las zonas suburbanas, incluso comienza a ser una práctica habitual en poblaciones pequeñas. En consecuencia, la seguridad es el rasgo más valioso para entender la vida urbana de hoy en día. Las nuevas murallas urbanas no son necesariamente grandes paredes divisorias, sino radares, cámaras de vídeo, detectores, escáneres... Se trata de toda clase artilugios tecnológicos que nos brindan seguridad, pero no para defendernos del miedo y la incertidumbre del mundo alejado y desconocido, sino más bien para aislarnos hermética e individualmente de los demás. No deja de ser paradójico que la seguridad se convierta en el nuevo paradigma de la sociedad del riesgo sobre todo

Si tomamos en cuenta que al avanzar el proceso histórico de modernización -cuya fase más reciente hoy llamamos globalización-, lo que asciende no es el nivel agregado de seguridad pública y bienestar humano -como sostenía la ingenua ideología del progreso continuo con que nació la modernidad ilustrada-, sino, por el contrario, el saldo neto de inseguridad colectiva y riesgo social. Así que cuanto más modernos nos hacemos, más peligrosa e incierta resulta la modernidad y más se incrementa la probabilidad de que ocurran crisis, catástrofes y desastres sin cuento (GIL CALVO, 2003, p.23).

\subsection{Seguridad Ciudadana Vigente}

En las sociedades tradicionales y comunidades urbanas más antiguas la seguridad se asociaba a la ayuda y se entiende como un bien adquirido, en cambio, en las sociedades actuales, la seguridad ciudadana se interpreta más bien como un bien adquirible, para reforzar los ineficientes y obsoletos bienes adquiridos que públicamente ofrecen las instituciones sociales (familia, escuela, iglesia, estado, hospitales, juzgados, etc.). Es obvio que la seguridad que compramos a las compañías privadas - con contratos a perpetuidad- no sirve para aclarar la confusión imperante en la que se vive, sino más bien sirve como una vía de escape para no ver ni pensar en la inseguridad, a pesar de percibir cotidianamente situaciones de incertidumbre.

El urbanismo contemporáneo, por su parte, ya no está tan comprometido en diseñar lugares públicos de encuentro (para intercambiar y compartir, para relacionarse y comunicarse con los demás), más bien el urbanismo vigente está comprometido en diseñar lugares públicos para el tránsito, la circulación, el libre paso, la movilidad de mercancías, de información y de 
personas; de aquí que "la ausencia de ágora (apunta PADOVÁN, 2004, p. 103) deja a los individuos aislados y con miedo, a merced de los peligros y riesgos de su alrededor".

La seguridad ciudadana vigente, valor paradigmático de la sociedad del riesgo, se estructura y se refuerza en función de los miedos socialmente compartidos y de los temores convencionalmente aceptados. Innerarity (2004, p.153) destaca que

Donde antes había carencias visibles hay ahora riesgos difusos. Las sociedades de clases estaban interesadas en la igualdad; las sociedades del riesgo se afanan por la seguridad. El vínculo de la necesidad ha sido sustituido por el vínculo del miedo, y los peligros visibles por los riesgos invisibles. Pero aquello que escapa de la percepción no se convierte en algo irreal; su escasa visibilidad puede incluso agudizar la inquietud y el sentimiento de inseguridad.

\section{LOS RIESGOS Y LAS CATÁSTROFES OCASIONADOS Y PERCIBIDOS POR EL HOMO CALAMITATEM}

El hombre de nuestros días, el que propicia catástrofes a partir de sus actividades productivas y dinámicas sociales, es el que en este artículo hemos denominado como homo calamitatem. Un hombre contemporáneo que, además, está muy acostumbrado a percibir los entornos sociales como si todo fuese catástrofe, debido, sobre todo, a las narrativas audiovisuales a las que está expuesto a diario a través de los medios de comunicación.

No nos equivocamos al afirmar que la percepción del riesgo y el conocimiento sobre los desastres se producen principalmente por las narrativas periodísticas. Sin embargo, el periodismo de catástrofes no sólo informa y reconfigura los riesgos y eventos extremos, sino que hace uso de fórmulas narrativas que "enseñan" al público a relacionarse con ellos. Por lo tanto, dicho periodismo también cumple con una función pedagógica al intentar explicar las causas de los desastres. En consecuencia, en el periodismo de catástrofes subyacen códigos culturalmente específicos para la narración de estos eventos/sucesos extremos (BIRD Y DARDENNE, 1999).

Hay que advertir que en las formas narrativas predominantes de las coberturas de desastres el homo calamitatem no se llega a conocer con claridad. O sea, las narrativas periodísticas no se refieren a él de forma específica, sino más bien de forma genérica adjudicando culpas y responsabilidades a todos o, a la postre, a ninguno. Por lo tanto, los auténticos causantes de las catástrofes quedan eximidos de cualquier clase de responsabilidad. Las formas de no adjudicar responsabilidades directas las encontramos, por ejemplo, en los 
relatos periodísticos que no relacionan la degradación ambiental con la acción humana ni hacen referencia a los problemas relacionados con la vulnerabilidad social. Si el periodismo de catástrofes no adjudica responsabilidades concretas la realidad desastrosa se percibe como si la furia incontenible de la naturaleza fuese la única causante de los desastre, y frente a la que no se puede hacer otra cosa que gestionarla mediante protocolos de emergencia que puedan garantizar la seguridad de la sociedad.

En la mayoría de los reportajes sobre desastres existe un encantamiento o fascinación con la fuerzas de la naturaleza. Ponte (2004) cita la asignación de acciones y el poder de los objetos inanimados en casos que involucran las tragedia: la lluvia mató, la evocación del destino o la suerte de las víctimas: fue en el momento equivocado en el lugar equivocado y la invocación del inexplicable: la velocidad del viento no visto.

Sin embargo, para que el periodismo de catástrofes muestre al detalle las acciones de los verdaderos responsables de las tragedias, y no del homo calamitatem en términos genéricos, debería preocuparse más por los variados y acuciantes temas medioambientales. Dichos problemas, y sus posibles soluciones, deberían tener más presencia, así como la acción de los sectores que desprecian el medio natural o penalizan el medio ambiente para promover sus negocios. Los medios hablan de los desastres como las consecuencias directas de la furia de la naturaleza, de la fatalidad o de la falta de planificación urbanística de las ciudades. Pero, ¿quiénes son realmente los responsables? El periodismo de catástrofes también debería tener una vigilancia permanente con respecto a la acción de los gobernantes que, por omisión o compromiso con grupos de intereses de la sociedad, no suelen poner en práctica políticas públicas que contribuyan de manera efectiva a la reducción de la degradación del medioambiente (BUENO, 2008).

En el periodismo de catástrofes hay una reducción del desastre al espacio/tiempo del incidente y al caos creado inmediatamente después. No hay pasado ni futuro, características típicas de una forma de presentación periodística que se pueden nombrar fait divers o noticias. Son informaciones sin contexto, sin causas ni consecuencias. Para Valencio (2012), la cobertura limitada a los días de la catástrofe, el desastre como natural y el alivio con el "volver a la normalidad" se compone de un trío que puede ser denominado como "mentira organizada".

El desastre tiene múltiples causas, pero algunas se relacionan directamente con el desarrollo de las ciudades con grandes desigualdades sociales. Existe un encubrimiento del protagonismo humano concreto en la producción de las catástrofes y una creencia de que la prevención va sólo por las acciones de gestión puntuales y específicas. 
Las coberturas informativas de desastres son rehenes de una lógica en la que es más fácil mencionar un "desastre natural" como he señalado Baumann (2008) ocultando las responsabilidades reales y concretas. Los orígenes de la culpabilidad sobre lo que ocurre se encuentran en un lejano y nebuloso "allá arriba" y el efecto de la responsabilidad es "flotante", por lo que es prácticamente imposible localizar y asignar con precisión al culpable, transformándolo, para todo el mundo y a efectos prácticos, en la responsabilidad de nadie.

Sin embargo, como dice Dupuy (2006), es la vulnerabilidad social la que transforma el fenómeno en una catástrofe. El huracán Katrina que azotó los Estados Unidos en 2005, por ejemplo, fue la marca de un evento que algunos periódicos estadounidenses consideraron como un desastre hecho por el hombre (DUPUY, 2006 y BAUMANN, 2008). Es decir, durante la cobertura periodística del huracán, algunos periodistas y médios de comunicación decidieron alejarse de las líneas editoriales convencionales y contaron abiertamente la distribución selectiva de la inmuidad y sus efectos. Los estragos y las pérdidas humanas ocasionadas por el huracán mostraron cómo el marcador de raza y clase se hizo presente. Sin embargo fue una excepción, pues las narrativas periodísticas más comunes fueron la naturalización acrítica de un homo urbanus. La distribución equitativa del miedo diluyó responsabilidades, especialmente las responsabilidades públicas y políticas.

El homo calamitatem se refiere a una cultura que involucra a todos, sean ciudadanos, empresarios o políticos. Sin embargo, a estos últimos se prevé una mayor responsabilidad. Para Serra (2006) es precisamente en relación con los desastres que la naturaleza de la política contemporánea se revela con claridad, porque el político tiene la obligación de demostrar que los desastres no se deben a él. Serra cita los verbos utilizados en los discursos de los políticos tales como "prever" o "planear" que se sustituyen cada vez más por fórmulas como "yo espero", “уо creo". O sea, la responsabilidad está en algún lugar entre la astrología y la meteorología.

Parece que el ethos de la competencia, muy utilizado en las disputas electorales, desaparece en el discurso de los políticos y en las narrativas periodísticas de los desastres. Por lo tanto, el hombre desastroso sobrevive en una lógica que no es denunciada. En este juego de las escondidas, el homo calamitatem percibe las catástrofes reafirmando que el desastre no tiene nada que ver con él en particular, sino con todos en general, o con la fatalidad y la desgracia. Las ciudades crecen desordenadamente y el esquema narrativo periodístico predominante es que los riesgos son para todos y necesitamos de acciones de prevención para el día en que ocurra una catástrofe. Frente a las catástrofes quizá no deberíamos saberlo todo, 
pues conocer al detalle el origen de las responsabilidades (personajes públicos, instituciones contaminantes, grupos de presión, etc.) podría ser demasiado revelador.

\section{CONCLUSIÓN}

Cuando se borran y se distorsionan las fronteras de las ciudades y de los países, cuando es posible moverse en muchas direcciones pero llegar cada vez a menos destinos, cuando escasean las referencias fiables, cuando crecen la desorientación y la percepción de vulnerabilidad a padecer un daño irreparable, el individuo reclama un mínimo de seguridad que lo proteja del miedo, no del desconocimiento.

No hay que olvidar que lo que le ayudó al homo urbanus a desarrollar y a progresar como homo urbanitas o protagonista de la vida urbana fue la habilidad de saber distinguir de los entornos circundantes (ya sean naturales o urbanos) los aspectos que más le concernían y le comprometían para sobrevivir individual y colectivamente; sin embargo lo que en los momentos actuales nos atenaza y nos deja indefensos, ante los riesgos catastróficos de nuestra época, es precisamente lo contrario, la falta de interés y de habilidad para saber apreciar lo que más nos incumbe, concierne y nos compromete. Al no tener mucha ambición por armonizar la vida urbana y los entornos naturales nos conformamos con sobrevivir con lo puesto, egoístamente, "mientras no me pase nada". De todas formas, exigir ahora seguridad como un derecho ciudadano es un planteamiento sin capacidad de respuesta porque la vida urbana ya no tiene la antigua capacidad de defensa ni existen lugares en nuestras ciudades totalmente invulnerables ni con protecciones absolutas.

Tanto el homo urbanus como el homo urbanitas eran (y son) hombres proactivos, transformadores, conscientes de lo que tienen que hacer para mantener su estado de supervivencia y procurar la seguridad social, sin embargo, el homo calamitatem, es la definición de un hombre más bien pasivo, conformista, inconsciente de lo que tiene que hacer para saber sobrevivir, confundido por la latente inseguridad que percibe y preso de la información mediática muy volcada en coberturas de catástrofes que suelen interpretar los entornos próximos y lejanos como si se tratasen de catástrofes permanentes. El homo calamitatem provoca catástrofes por su forma de consumir, de relacionarse, de concebir su existencia en el espacio/tiempo que le ha tocado vivir, pero sobre todo, el homo calamitatem es una víctima directa o indirecta (virtual y a distancia) del acontecer de catástrofes que le ocasiona un fuerte sentimiento de inseguridad. 
Así pues, para terminar, nos quedamos con una idea de Castro e Danowski (2014), quienes dicen que el Antropoceno es el último período en la historia del mundo en que el hombre ya no es solamente agente biológico para convertirse en una fuerza geológica capaz de cambiar el paisaje del planeta y poner en peligro su propia supervivencia como especie y de otros seres vivos. O, para decirlo de otra manera, el punto de inflexión en que los humanos penas temen a la catástrofe pero se conviertem en la propia catástrofe.

\section{REFERENCIAS}

AUGÉ, M. Los no lugares: espacios del anonimato, una antropología de la sobremodernidad. Barcelona, Gedisa, 1993.

BAUMAN, Z. Medo Líquido. Rio de Janeiro: Zahar, 2008

BECK, U. La irresponsabilidad organizada. Debats, Valencia, n.2, p. 35-36, 1991.

BECK, U.; GIDDENS, A.; LASH, S. Modernización reflexiva: política, tradición y estética en el orden social moderno. Madrid: Alianza, 1997.

BIRD, Elisabet; DARDENNE, Robert. Mito, registro e "estórias": explorando as qualidades narrativas das notícias. In: TRAQUINA, N. (Org.) Jornalismo: questões, teorias e "estórias". 2. ed. Lisboa: Vega, 1999. p. 263-277.

BUENO, Wilson. Jornalismo ambiental: explorando além do conceito. In: GIRARDI, I.; SCHWAAB, R. (Org.). Jornalismo ambiental: desafios e reflexões. Porto Alegre: Dom Quixote, 2008, p. 105-118.

CASTRO, V.; DANOWSKI, D. Há mundos por vir? Ensaios sobre os medos e os fins. Cultura e Barbárie e Desterro, Florianópolis, 2014.

CAZ ENJUTO, Rosario del. Rasgos de un urbanismo no violento. Informe Valladolid Los derechos humanos y la ciudad, Valladolid, 2002.

DELGADO, M. El animal público. Barcelona: Anagrama, 1999.

DUPUY, J. Ainda há catástrofes naturais? Revista Análise Social, Lisboa. v181, p. 11811193, 2006.

ECHEVERRÍA, J. Cosmopolitas domésticos. Barcelona: Anagrama, 1995.

Los señores del aire: Telépolis y el tercer entorno. Barcelona: Destino, 1999.

FARRÉ COMA, J. Comunicación de riesgo y espirales del miedo. Comunicación y Sociedad, Guadalajara, n. 3, 2005. 
GARCÍA ACOSTA, V. La perspectiva histórica en la antropología del riesgo y del desastre. Acercamientos metodológicos. Relaciones CIESAS, México, n. 97, 2004.

GARCÍA GONZÁLEZ, G. La conformación de la moderna prensa informativa In GÓMEZ MOPAR, J.L.; MARÍN OTTO, E. Historia del periodismo universal. Madrid: Síntesis, 1999.

GIDDENS, A. Un mundo desbocado: los efectos de la globalización en nuestras vidas. Madrid: Taurus, 2002.

GIL CALVO, E. El miedo es el mensaje: riesgo, incertidumbre y medios de comunicación. Madrid: Alianza, 2003.

GRAHAM, S. Las ciudades como sitios estratégicos: La urbanización de la guerra y la militarización del espacio urbano. Informe Valladolid Sobre el derecho a la seguridad, Valladolid, 2004.

INNERARITY, D. La sociedad invisible. Madrid: Espasa, 2004.

LEÓN RODRÍGUEZ, R. Ciudades inseguras, blindaje urbano y simulacro urbanístico. Informe Valladolid Sobre el derecho a la seguridad, Valladolid, 2004.

LÓPEZ C., ANTONIO, J. y LUJÁN, J. Ciencia y política del riesgo. Madrid: Alianza, 2002.

LOZANO ASCENCIO, C. La percepción social de la incertidumbre o la facilidad que tenemos para sentirnos inseguros. Informe Valladolid Sobre el derecho a la seguridad, Valladolid, 2004.

MANSILLA, E. Riesgo y ciudad. La Red - Red de estudios sociales en prevención de desastres en América Latina, Mexico, dez. 2000. Disponível em <http://www.desenredando.org/public/libros/2000/ryc/index.html>. Acesso em 6 set. 2015.

PADOVAN, D. Capital social, inseguridad y miedo al crimen en Padua. Informe Valladolid Sobre el derecho a la seguridad, Valladolid, 2004.

PONTE, C. Leituras das Notícias: contributos para uma análise do discurso jornalístico Lisboa, Livros Horizontes, 2004.

RAMENTOL, S. Teorías del desconcierto, viaje al fondo de la incertidumbre: los pensadores que diseñan un futuro global. Barcelona: Tendencias, 2004.

REGUILLO CRUZ, R. La construcción simbólica de la ciudad: sociedad, desastre y comunicación. Guadalajara, ITESO, 1996.

SERRA, Joaquim Paulo. Cataclismos e catástrofes: reflexões acerca da relação entre sistema político e sistema mediático. Universidade da Beira Interior, Convilhã. 2006. Disponível em http://www.bocc.ubi.pt/pag/serra-paulo-cataclismos-catastrofes.pdf. Acesso em 2 mar. 2011.

VALENCIO, N. Para além do "Dia do Desastre": o caso brasileiro. Curitiba: Appris, 2012. 
Original recebido em: 19/11/2015

Aceito para publicação em: 04/12/2015

Carlos Lozano Ascencio

Doutor em Ciências da Informação pela Universidade Complutense de Madrid, pesquisador do Sistema Nacional de Investigadores do México

Márcia Franz Amaral Doutora em Comunicação e Informação pela Universidade Federal do Rio Grande do Sul, pesquisadora do Conselho Nacional de Pesquisa (CNPq)

Esta obra está licenciada sob uma Licença Creative Commons 